\title{
P013: Prevalence rate of healthcare associated infection in emergency critical care for surgery, burns and neurology ward
}

\author{
S Mehtar, JMV Namahoro* \\ From 2nd International Conference on Prevention and Infection Control (ICPIC 2013) \\ Geneva, Switzerland. 25-28 June 2013
}

\section{Introduction}

Many Healthcare Associated Infections (HAI) are related to the use of a medical device, especially invasive devices that buy-pass the normal barriers to entry of microorganisms into the body. HAI rates of CA-UTI, CLA-BSI and VAP are significantly greater among patients when a medical device is used.

\section{Objectives}

Determine Healthcare Associated infection risk with medical devices.

To make recommendations for performance improvement.

\section{Methods}

Observation study of pilot study. Data was collected for a period of five weeks. Active surveillance by considering laboratory results and regular visits to patients in respiratory intensive care unit was a method used to assess patients at-risk of healthcare associated infection. The Structured audit sheet was used.

\section{Results}

The sample consisted of $92 \%$ patients received urinary catheter, $83 \%$ patients are exposed on the peripheral lines, 50\% patients obtained central lines and 58\% patients acquired endotracheal tube in situ. The mean length of stay was 4.04. The prevalence rate of HAI was $50 \%$ infections. The predominance of prevalnce rate was found for VAP by $36 \%$, while incidence rate of CLA-BSI was $25 \%$ and incidence rate in CA-UTI with Urinary tract infection was $14 \%$.

\section{Conclusion}

The HAI is very high in $\mathrm{C} 1$ Resuscitation ward. The improved IPC practice is required and further research is needed to identify the effect of medical devices with prevalence of infection in $\mathrm{C} 1$ Resuscitation ward.

\section{Disclosure of interest \\ None declared.}

Published: 20 June 2013

\section{References}

1. Hajdu, et al: A point prevalence survey of hospital-acquired infections and antimicrobial use a paeditric hospital in north-western Russia. Journal of Hospital Infection 2007, 66(4):378-384.

2. Hajdu, et al: A point prevalence survey of hospital-acquired infections and antimicrobial use a paeditric hospital in north-western Russia. Journal of Hospital Infection 2007, 66(4):378-384.

3. Mary LM, et al: Basic Concepts of Infection Control. Portadown(N Ireland): International Federation of Infection Control; 22011.

4. Mehtar S: Understanding Infection Prevention and Control. Cape Town: Juta and Company Ltd; 12010.

5. Regina F, et al: Indwelling urinary catheter management and catheter associated urinary tract infection prevention practices in Nurses Improving Care for Healthsystem Elders hospitals. American Journal of Infection Control 2012, 40(8):715-720.

doi:10.1186/2047-2994-2-S1-P13

Cite this article as: Mehtar and Namahoro: P013: Prevalence rate of healthcare associated infection in emergency critical care for surgery, burns and neurology ward. Antimicrobial Resistance and Infection Control 2013 2(Suppl 1):P13. 